Down's syndrome 5-hydroxytryptamine imipramine monoamine oxidase serotonin thrombocytes

\title{
Down's Syndrome: Transport, Storage, and Metabolism of Serotonin in Blood Platelets
}

\author{
Ira T. Lott, Thomas N. Chase, and Dennis L. Murphy ${ }^{[36]}$ \\ Laboratory of Clinical Science, National Institute of Mental Health and the Children's Diagnostic and Study Branch, \\ National Institute of Child Health and Human Development, National Institutes of Health, \\ Bethesda, Maryland, USA
}

\begin{abstract}
Extract
Serotonin (5HT) transport and metabolism were studied in platelets from 14 trisomy21 patients who were matched with 12 sibling and 9 non-sibling control subjects with regard to age, sex, home environment, diet and weight. Endogenous $5 \mathrm{HT}$ content, in nanograms per milligram platelet protein, was reduced from $446 \pm 66$ in the sibling controls and from $492 \pm 74$ in the non-sibling controls to $158 \pm 16$ in the Down's syndrome group, a difference of $61 \%$ and $68 \%$ respectively $(P<0.001)$. Initial uptake of ${ }^{14} \mathrm{C}-5 \mathrm{HT}$ measured after a 3 -min incubation period was reduced $35 \%(P<0.05)$ in the platelets from Down's syndrome patients, while the efflux of radiolabeled amine from platelets was not significantly altered in these patients. Since platelets do not synthesize $5 \mathrm{HT}$, the decreased transport found may explain the lower 5HT levels in these patients. Mongols did not differ from control subjects in the activity of platelet monoamine oxidase.
\end{abstract}

\section{Speculation}

Similarities in the uptake, storage, and release of $5 \mathrm{HT}$ between the human blood platelet and the serotonergic neuron suggest that the $5 \mathrm{HT}$ abnormality observed in mongol platelets may reflect disordered metabolism of the monoamine within the central nervous system.

\section{Introduction}

Low levels of $5 \mathrm{HT}$ have been reported in whole blood $[25,27]$ and platelets [12, 18] from patients with Down's syndrome. Explanations for this biochemical abnormality have included alterations in the metabolism of 5HT [11, 14] or in the uptake, storage, or release $[4,13]$ of the amine by blood platelets, the cellular structures which contain virtually all the $5 \mathrm{HT}$ present in whole blood [22, 28]. The possibility that low levels of $5 \mathrm{HT}$ in platelets relate to the central nervous system defect in Down's syndrome is suggested by recent evidence that the human platelet has certain structural and functional similarities to amine-containing neurons [1, 19-21]. On the assumption that the whole blood abnormality of 5HT in Down's syndrome may reflect defective metabolism of this putative neurotransmitter amine in the central nervous system, L-5hydroxytryptophan, the immediate precursor of $5 \mathrm{HT}$, has been administered to neonatal mongols and has been shown to produce some alteration in neuromuscular function [2]. 
The patient populations in previous metabolic studies, when defined, have consisted of institutionalized mongols, a source which may distort biochemical observations through the influence of diet and intercurrent disease [29]. The present study was designed to evaluate aspects of $5 \mathrm{HT}$ metabolism in the platelets of Down's syndrome patients who were matched with control subjects in regard to age, sex, home environment, diet and weight.

\section{Patients and Methods}

Fourteen individuals [33], 9 males and 5 females, 8-25 years old, with the clinical characteristics of Down's syndrome were found to have trisomy-21 by karyotype analysis. All patients lived at home and attended day care centers for retarded children. Each was found to be free of intercurrent disease by medical evaluation.

The first control group consisted of 12 non-mentally retarded siblings [33] (7 males and 5 females, 7-24 years old) of the Down's syndrome patients who lived in the same household. The second control group was composed of 9 non-sibling controls [33] (5 males, 4 females) who were aged matched with the Down's syndrome patients. Laboratory studies of the Down's syndrome patients and their siblings were performed in batches with patient and control samples equally distributed on each study day. All blood samples were coded before analysis. Medications, if any, were discontinued at least $2 \mathrm{wk}$ prior to the study and a dietary history was used to exclude ingestion of unusual foods. Foods containing high concentrations of $5 \mathrm{HT}$ were excluded for a period beginning $48 \mathrm{hr}$ prior to collection of blood.

All blood was drawn between 9 and 11 AM. Venous blood containing 10 units heparin $/ \mathrm{ml}$ was centrifuged at $125 \times g$ for $20 \mathrm{~min}$ to yield platelet-rich plasma with an average of one leukocyte per $10^{5}$ platelets. Uptake of $5 \mathrm{HT}$ was measured by incubation of platelet-rich plasma with ${ }^{14} \mathrm{C}$-5-hydroxytryptamine creatinine sulfate $(40 \mathrm{mCi} / \mathrm{mmole})$ [32] and harvesting of aliquots of the suspended platelets by centrifugation $(12,000 \times g)$ after 3-and 30-min periods of incubation. Labeled amine was extracted from the platelet pellet into $0.4 \mathrm{~N}$ perchloric acid and counted by liquid scintillation spectrometry. The radiolabeled compound was identified by thin layer chromatography with authentic indoleamines used as carriers [15]. Platelet protein content was determined by the method of Lowry et al. [16] on aliquots from the $12,000 \times g$ platelet pellet washed with isotonic saline.
Table I. Endogenous serotonin content of platelets

\begin{tabular}{lc}
\hline \multicolumn{1}{c}{ Subjects } & Serotonin, ng/mg protein \\
\hline Down's syndrome $(n=14)$ & $158 \pm 16^{1}$ \\
Down's syndrome siblings $(n=12)$ & $446 \pm 66$ \\
Non-sibling control subjects $(n=9)$ & $492 \pm 74$ \\
\hline I $P<0.001 ;$ mean \pm sE.
\end{tabular}

In other experiments, ${ }^{14} \mathrm{C}-5 \mathrm{HT}$ was added directly to fresh platelet-rich plasma to yield a final concentration of $1 \times 10^{-6}$ M. After 30 min, platelets were sedimented by centrifugation at $1100 \times g$, then washed with isotonic saline and resuspended in either autologous plasma or Tris-phosphate buffer ( $\mathrm{pH} 7.2$ ) that contained glucose $(5.9 \mathrm{~mm})$ and $3.2 \%$ sodium citrate. These preparations were reincubated at $37^{\circ}$ and aliquots were harvested after 30 and $60 \mathrm{~min}$. The ${ }^{14} \mathrm{C}$ $5 \mathrm{HT}$ which was retained in the platelets was extracted and quantitated by the same methods as were used in the uptake studies.

Levels of $5 \mathrm{HT}$ in platelets were measured fluorometrically [26] and platelet monoamine oxidase activity was determined by the deamination of $2^{14} \mathrm{C}$-tryptamine, $8 \times 10^{-5} \mathrm{M}[30]$.

\section{Results}

Endogenous 5HT content was reduced by $61 \%$ in the Down's syndrome group as compared with sibling controls $(P<0.001)$ and by $68 \%$ in comparison with non-sibling controls $(P<0.001)$ (Table I). Concentration of protein in platelets, in micrograms per milliliter platelet-rich plasma, was $450 \pm 97$ for sibling controls, $565 \pm 80$ for non-sibling controls, and $564 \pm 67$ for the Down's syndrome group. The differences were not statistically significant. There were no differences in hematocrits, white blood cell counts or platelet counts between mongol and control groups.

\section{Uptake of $5 H T$ by Mongol and Control Platelets}

The ${ }^{14} \mathrm{C}-5 \mathrm{HT}$ content of platelets which had been incubated for $3 \mathrm{~min}$ was determined in order to measure the initial rate of amine uptake (i.e., at a time when vesicular binding and storage processes exert relatively little influence on the concentration of radioactivity) [19]. The use of radiolabeled 5HT permitted measurement of amine uptake at early time periods. The 3-min time point with a final ${ }^{14} \mathrm{C}-5 \mathrm{HT}$ concentration of $10^{-6} \mathrm{M}$ provides a measure of the initial rate of amine uptake at the cellular membrane which was found to be linear for only $5 \mathrm{~min}$ [11]. A greater con- 
Table II. Uptake of ${ }^{14} \mathrm{C}$-serotonin by platelets

\begin{tabular}{|c|c|c|}
\hline \multirow[b]{2}{*}{ Subjects } & \multicolumn{2}{|c|}{$\begin{array}{l}{ }^{14} \mathrm{C} \text {-serotonin uptake, } \\
\text { pmoles/mg protein }\end{array}$} \\
\hline & $\begin{array}{l}\text { 3-min } \\
\text { incubation, } \\
1 \times 10^{-6} \text { M }\end{array}$ & $\begin{array}{l}\text { 20-min } \\
\text { incubation, } \\
1 \times 10^{-5} \mathrm{M}\end{array}$ \\
\hline Down's syndrome $(n=14)$ & $227 \pm 19^{1}$ & $1240 \pm 97^{2}$ \\
\hline $\begin{array}{l}\text { Down's syndrome siblings } \\
\quad(n=12)\end{array}$ & $339 \pm 45$ & $1740 \pm 330$ \\
\hline $\begin{array}{l}\text { Non-sibling control subjects } \\
\quad(n=9)\end{array}$ & $392 \pm 55$ & $1850 \pm 320$ \\
\hline
\end{tabular}

suspended in platelet-poor plasma obtained from each subject. Platelets from the Down's syndrome patients had a significantly lower concentration of the amine at the time of resuspension, which reflected the above-described differences in 5HT uptake and binding. However, loss of ${ }^{14} \mathrm{C}-5 \mathrm{HT}$ from platelets resuspended for 30 and $60 \mathrm{~min}$ increased only moderately $(6-8 \%)$ in the mongol group and this did not represent a significant difference when compared with the control subjects (Table III). When prelabeled platelets were suspended in 5HT-free buffer instead of in autologous plasma, uptake and release results were virtually identical to those cited above.

Table III. Efflux of ${ }^{14} \mathrm{C}$-serotonin from platelets

\begin{tabular}{|c|c|c|c|c|c|}
\hline \multirow{3}{*}{ Subjects } & \multicolumn{5}{|c|}{ Minutes } \\
\hline & \multirow{2}{*}{$\frac{0}{\text { pmoles/mg protein }}$} & \multicolumn{2}{|c|}{30} & \multicolumn{2}{|c|}{60} \\
\hline & & pmoles/mg protein & $\%$ change from 0 time & pmoles/mg protein & $\%$ change from 0 time \\
\hline Down's syndrome $(n=14)$ & $520 \pm 38$ & $445 \pm 39$ & $(-14.1 \%)$ & $443 \pm 39$ & $(-14.5 \%)$ \\
\hline Down's syndrome siblings $(n=12)$ & $736 \pm 83$ & $688 \pm 92$ & $(-6.1 \%)$ & $673 \pm 72$ & $(-8.2 \%)$ \\
\hline
\end{tabular}

Table $I V$. Monoamine oxidase (MAO) activity in platelets

\begin{tabular}{lc}
\hline \multicolumn{1}{c}{ Subjects } & $\begin{array}{c}\text { MAO activity, } \\
\text { nanomoles/mg protein/hr }\end{array}$ \\
\hline Down's syndrome $(n=14)$ & $4.48 \pm 0.37$ \\
Down's syndrome siblings $(n=12)$ & $5.11 \pm 0.76$ \\
\hline
\end{tabular}

centration of ${ }^{14} \mathrm{C}-5 \mathrm{HT}\left(1 \times 10^{-5} \mathrm{M}\right)$ and a longer incubation period $(20 \mathrm{~min}$ ) was used in order to saturate the transport mechanism and to determine intracellular (including intravesicular) binding capacity. In this experiment, platelets from Down's syndrome patients incorporated significantly less $(P<0.05)$ radioactivity than did platelets from either of the control groups (Table II). When platelets were incubated for 20 min with a 10 -fold greater concentration of ${ }^{14} \mathrm{C}$ $5 \mathrm{HT}$, a similar difference in the accumulation of $5 \mathrm{HT}$ in platelets was observed, although greater variance in individual values resulted in borderline statistical significance $(P=0.10)$. When the two control groups were combined and compared with the Down's syndrome group, the differences achieved statistical significance $(P<0.05)$. Assay of radioactivity indicated that over $95 \%$ was in $5 \mathrm{HT}$.

\section{HT Storage and Efflux from Platelets}

The amount of 5HT retained by platelets during prolonged incubation was measured by observing the $5 \mathrm{HT}$ content of ${ }^{14} \mathrm{C}-5 \mathrm{HT}$ loaded cells which were re-

\section{Monoamine Oxidase Activity}

In order to determine whether the depressed content of $5 \mathrm{HT}$ in mongol platelets could be related to an increased rate of enzymatic degradation, monoamine oxidase activity was measured using ${ }^{14} \mathrm{C}$-tryptamine as substrate. Mongols did not differ from control subjects with respect to monoamine oxidase activity (Table IV).

\section{Effects of Imipramine on the Efflux of $5 H T$ from Platelets}

The 5HT which is released from platelets can be taken up again by a specific membrane transport mechanism [8]. Thus the low content of $5 \mathrm{HT}$ in mongol platelets, or the reportedly increased rate of $5 \mathrm{HT}$ release from prelabeled platelets resuspended in $5 \mathrm{HT}$ free plasma [4], may be due to a continuing defect in the reuptake of the amine as well as to defective binding. Imipramine competitively inhibits accumulation of $5 \mathrm{HT}$ by platelets $[10,17,31]$ and was used to examine whether a loss of the amine similar to that observed in the Down's syndrome patients might be observed when reuptake was blocked to a similar degree $(30-40 \%)$. Imipramine $\left(10^{-\tau} \mathrm{M}\right)$ added in vitro produced a $10-20 \%$ greater loss of ${ }^{14} \mathrm{C}-5 \mathrm{HT}$ from the platelets of both mongol and control subjects $(P<$ 0.05 , Fig. 1). 


\section{Discussion}

Alterations in the $5 \mathrm{HT}$ content of platelets might be explained by differences in systemic synthesis, or by changes in the release, uptake, or binding of the amine. Our results indicate that the endogenous $5 \mathrm{HT}$ content of platelets from Down's syndrome patients is markedly reduced and that the initial rate of $5 \mathrm{HT}$ uptake by these platelets is depressed. Since platelet $5 \mathrm{HT}$ is thought to derive predominantly from the uptake of circulating $5 \mathrm{HT}$ rather than from synthesis in the platelet, the altered transport of 5HT observed provides a mechanism for explaining the change in endogenous 5HT levels. The low endogenous content is in agreement with that reported in several other studies [1-4], and a defect in the total accumulation of $5 \mathrm{HT}$ by mongol platelets was previously reported by Jerome and Kamoun using high concentrations of nonradiolabeled 5HT [13].

In contrast, storage of $5 \mathrm{HT}$ as measured by the rate of release of ${ }^{14} \mathrm{C}-5 \mathrm{HT}$ during prolonged incubation is not significantly altered in these patients. Measurement of storage of $5 \mathrm{HT}$ in platelets is complex because of the reuptake of the slowly released amine which occurs when prelabeled platelets are resuspended in 5HT-free plasma or buffer solutions. We have shown that an increased loss of radioactivity occurs when prelabeled platelets are incubated with imipramine, which suggests that the reuptake of released 5HT is at least one factor that is necessary in order to maintain concentration of amine in platelets. The concentration of imipramine used in this study, which is comparable to levels in plasma achieved clinically in man, probably does not directly cause the release of significant amounts of endogenous 5HT which, however, can occur with much higher drug concentrations $\left(10^{-4} \mathrm{M}\right)$ [24]. The effect of imipramine is small at $10^{-7} \mathrm{M}$ concentrations, but a definite loss of platelet 5HT was observed which is of the same order of magnitude as that seen in the release experiments with Down's syndrome patients. This indicates that the degree of diminished 5HT uptake observed in Down's syndrome platelets is sufficient to account for the small increase in amine "release" seen in these patients. In this regard, it is interesting to note a previous study [4] on the efflux of $5 \mathrm{HT}$ from mongol platelets in which the concentration of platelet $5 \mathrm{HT}$ was decreased approximately $50 \%$ in the Down's syndrome group at the end of the preincubation period, a finding that is in agreement with our own (Table III). It seems entirely possible that the low content of $5 \mathrm{HT}$ at the time of resuspension is related to defective uptake of the amine as well as to the observed increased rate of "release".

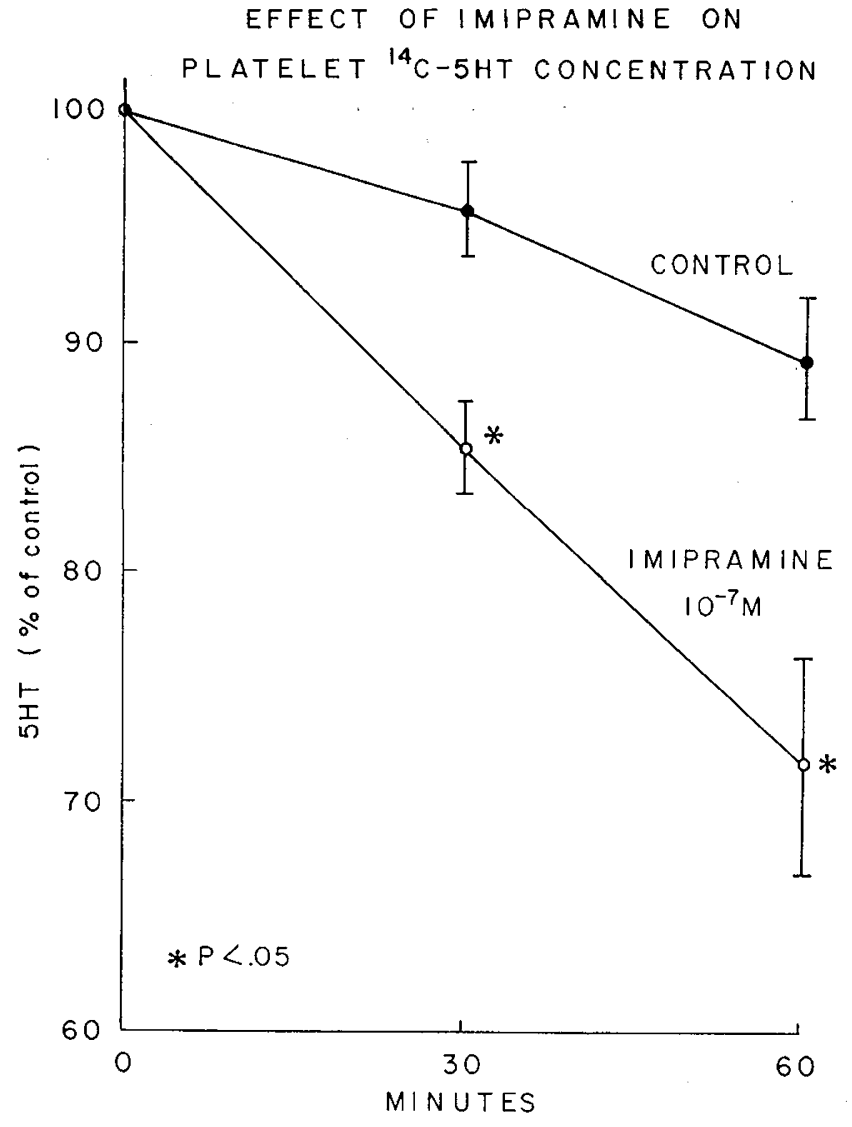

Fig. 1. Effect of imipramine on concentration of ${ }^{14} \mathrm{C}$-serotonin $(5 \mathrm{HT})$ in platelets.

Platelets contain high concentrations of ATP [7] and the suggestion by Born et al. [9] that 5HT was bound to ATP in human platelets has been supported by recent evidence [3]. ATP has also been implicated in an active transport system for 5HT at the cellular membrane [23]. Consequently, decreased uptake of $5 \mathrm{HT}$ by mongol platelets might be explained by a defect in platelet ATP content or function. A decrease in total ATP concentration has recently been suggested for Down's syndrome patients [5], but this has not been confirmed in other studies [13].

Since the catabolic route for $5 \mathrm{HT}$ is oxidative deamination, the finding of normal monoamine oxidase activity in Down's syndrome platelets makes it unlikely that the low endogenous content of 5HT is a direct result of increased degradation of 5HT. The possibility remains that defective synthesis of the amine by enterochromaffin cells located in the gastrointestinal tract contributes to the low $5 \mathrm{HT}$ content of mongol platelets.

Although the low content of 5HT in Down's syndrome platelets has no known clinical significance, the 
similarities between human blood platelets and amine-containing neurons make imperative a comparative study of $5 \mathrm{HT}$ metabolism in human blood platelets and brain.

\section{Summary}

Endogenous $5 \mathrm{HT}$ content of blood platelets was reduced by $60-70 \%$ in Down's syndrome patients as compared with a group of sibling and non-sibling control subjects. The initial uptake of radiolabeled $5 \mathrm{HT}$ was reduced by $35 \%$ in the Down's syndrome group, although efflux of the amine and activity of monoamine oxidase were not altered in these patients. The decreased transport of $5 \mathrm{HT}$ into the blood platelet may explain the low level of this amine in the blood of Down's syndrome patients.

\section{Addendum}

As this paper was being prepared for publication, Boullin and O'Brien [6] reported results that are in agreement with our findings of low content of $5 \mathrm{HT}$ in platelets, and defective uptake of the amine by mongol platelets. In addition, they observed an increased rate of ${ }^{14} \mathrm{C}-5 \mathrm{HT}$ efflux from mongol platelets which was associated with a low ATP concentration. The difference from our finding of no significant increase in ${ }^{14} \mathrm{C}-5 \mathrm{HT}$ efflux may possibly be related to methodological differences, including their use of ethylenediaminetetraacetic acid as anticoagulant. They also stated the need for a study of 5HT in brain of Down's syndrome patients.

\section{References and Notes}

1. Abrams, W. B., And Solomon, H. M.: The human platelet as a pharmacologic model for the adrenergic neuron. Clin. Pharm. Ther., 10: 702 (1969).

2. Bazelon, M., Paine, R. S., Cowie, V. A., Hunt, P., Houck, J. D., AND MANAHAND, D.: Reversal of hypotonia in infants with Down's syndrome by administration of 5-hydroxytryptophan. Lancet, $i$ : 1130 (1967).

3. Berneis, K. H., Da Prada, M., and Pletscher, A.: Micelle formation between 5 -hydroxytryptamine and adenosine triphosphate in platelet storage organelles. Science, 165: 913 (1969).

4. Boullin, D. I., Coleman, M., and O'Brien, R. A.: Defective binding of 5-HT by blood platelets from children with the trisomy 21 form of Down's syndrome. J. Physiol., 204: 128 (1969).

5. Boullin, D. J., Coleman, M., and O'Brien, R. A.: Abnormalities in platelet 5-hydroxytryptamine efflux in patients with infantile autism. Nature, 226: 371 (1970).

6. Boullin, D. J., ANd O'Brien, R. A.: Abnormalities of 5-hydroxytryptamine uptake and binding by blood platelets from children with Down's syndrome. J. Physiol., 212: 287 (1971).

7. BorN, G. V. R.: Adenosine triphosphate (ATP) in blood platelets. Biochem. J., 62: 33 (1956).

8. Born, G. V. R., AND Gillson, R. E.: Studies on the uptake of 5-hydroxytryptamine by blood platelets. J. Physiol., 146: 472 (1959).

9. Born, G. V. R., Ingram, G. I. C., and Stacey, R. S.: The relationship between 5-hydroxytryptamine and adenosine triphosphate in blood platelets. Brit. J. Pharmacol., 13: 62 (1958).

10. Fuks, Z., Lanman, R. C., and Schanker, L. S.: On the membrane effects of chlorpromazine: uptake of biologic amines by the blood platelet and red cell. Int. J. Neuropharmacol., 3: 623 (1964).

11. Jerome, H., And Kamoun, P.: Diminution du taux de la serotonine associee a un defaut de captetion dans les plaquettes sanguines des sujets trisoniques. Compt. Rend. Acad. Sci. (Paris), 264: 2072 (1967).

12. Jerome, H., And Kamoun, P.: Anomalie de la captation de la serotonine par plaquettes sanguines des sujets trisomiques 21. I. Etude des caracteristiques generales de la captation. Bull. Soc. Chim. Biol., 50: 907 (1968).

13. Jerome, H., and Kamoun, P.: Platelet binding of serotonin. Annals N.Y. Acad. Sci., 171: 543 (1970).

I4. Jerome, H., Lejeune, J., and Turpin, R.: Etude de excretion urinaire de certains metabolites du tryptophan chez les enfants mongoliens. C. R. Acad. Sci. Paris, 251: 474 (1960).

15. KlerN, D. C., AND Notrdes, A.: Thin-layer chromatographic separation of pineal gland derivates of serotonin $-{ }^{14} \mathrm{C}$. Analyt. Biochem., 31: 408 (1969).

16. Lowry, O. H., Rosebrough, N. J., Farr, A. L., and Randall, R. J.: Protein measurement with the Folin phenol reagent. J. Biol. Chem., 193: 265 (195I).

17. Marshall, E. F., Stirling, G. S., Tair, A. C., and Todrick, A.: The effect of iproniazid and imipramine on the blood platelet 5-hydroxytryptamine level in man. Brit. J. Pharmacol., 15: 35 (1960).

18. McCoy, E. E., Rostafinsky, M. J., and Fishburn, C.: The concentration of serotonin by platelets in Down's syndrome. J. Ment. Defic. Res., 12: 18 (1968).

19. Murphy, D. L., Colburn, R. W., Davis, J. M., and Bunney, W. E.: Imipramine and lithium effects on biogenic amine transport in depressed and manic-depressed patients. Amer. J. Psychiat., 127: 339 (1970).

20. Murphy, D. L., and Korrn, I. J.: The transport of biogenic amines. In: L. E. Hokin: Cell Transport and Metabolism. (Academic Press, New York, in press).

21. PaAsonen, M. K.: Platelet 5-hydroxytryptamine as a model in pharmacology. Ann. Med. Exp. Fenn., 46: 416 (1968).

22. Page, I. H.: Serotonin (5 hydroxytryptamine); the last four years. Physiol. Rev., 38: 277 (1958).

23. Pletscher, A., Burkard, W. P., Tranzer, J. P., and Gey, K. F.: Two sites of 5-hydroxytryptamine uptake in blood platelets. Life Sci., 6: 273 (1967).

24. Pletscher, A., and Tranzer, J. P.: Action of reserpine and imipramine on intracellular storage of 5 -hydroxytryptamine in blood platelets. Experientia, 23: 298 (1967).

25. Rosner, F., Ong, B. H., and Paine, R. S.: Blood serotonin activity in trisomic and translocation Down's syndrome. Lancet, $i: 1191$ (1965).

26. Snyder, S. H., Axlerod, J., ANd Zweig, M.: A sensitive and 
specific fluorescence assay for tissue serotonin. Biochem. Pharm., 14: 831 (1965).

27. Tu, J. D., AND Zellawferer, H.: Blood serotonin deficiency in Down's syndrome. Lancet, ii: 715 (1965).

28. Unentriend, S., AND Weissbach, H.: Studies on serotonin (5 hydroxytryptamine) in platelets. led. Proc., 13:412 (1954).

29. WoOdFord, P. F., AND BEARN, A. G.: A critical examination of some reported biochemical abnormalities in mongolism. Ann. N.Y. Acad. Sci., 171: 551 l (1970).

30. Wurtman, R. J., AND Axleron, J.: A sensitive and specific assay for the estimation of monoamine oxidase. Biochem. Pharm., 12: 1139 (1963).

31. Yates, C. M., Todrick, A., And TaIt, A. C.: Effect of imipramine and some analogues on the uptake of 5 -hydroxytryptamine by human blood platelets in vitro. J. Pharm. Pharmacol., 16: 460 (1964).
32. New England Nuclear Corporation, Boston, Mass.

33. Informed consent for participating in the study was obtained from parents of patients and control subjects in accordance with the provisions set forth in the Declaration of Helsinki.

34. We are gratcful to Dr. Matti S. Al-Aish for performing karyotype analysis of the Down's syndrome patients and to Cynthia Donnelly for her technical assistance.

35. 'This work was presented in part at the 23rd Annual Mecting of the American Academy of Neurology, New York City, April 29-May 1, 1971.

36. Requests for reprints should be addressed to: DFNis L. Murpyx, M.D., National Institutes of Health Clinical Center, 10-3S229, Bethesda, Maryland 20014 (USA).

37. Accepted for publication April 17, 1972. 